\title{
ATMOSPHERIC PLASMA TREATMENT OF ITO THIN FILMS FOR RAPID MANUFACTURING OF PEROVSKITE SOLAR CELLS
}

\author{
${ }^{1}$ Tomáš HOMOLA, ${ }^{1}$ Masoud SHEKARGOFTAR, ${ }^{2}$ Jan POSPIŚIL \\ ${ }^{1} R \& D$ Center for Low-Cost Plasma and Nanotechnology Surface Modifications (CEPLANT), Department \\ of Physical Electronics, Faculty of Science, Masaryk University, Brno, Czech Republic, \\ tomas.homola@mail.muni.cz \\ ${ }^{2}$ Faculty of Chemistry, Brno University of Technology, Brno, Czech Republic, \\ xcpospisil@fch.vut.cz
}

https://doi.org/10.37904/nanocon.2019.8645

\begin{abstract}
Prevailing modes of the manufacture of modern energy-harvesting systems and other electronics based on silicon fail to meet the requirements of the steps involved in low-cost fabrication. Rapid and low-cost roll-to-roll manufacture - the future of commercialization for flexible and printed electronics - requires flexible and lowcost substrates such as polyethylene terephthalate, polyethylene naphthalate and, more recently, green materials such as nano-paper. The temperature at every single fabrication stage is crucial with such materials and cannot exceed a certain threshold, generally $150{ }^{\circ} \mathrm{C}$ or less. Low-temperature plasma, therefore can provide an excellent way forward for future manufacturing methods.

This contribution presents a proprietary, large-area plasma of extremely high-volume power density, up to 100 $\mathrm{W} / \mathrm{cm}^{3}$, capable of generating diffuse, homogeneous and cold plasma $\left(<70{ }^{\circ} \mathrm{C}\right)$ in the open air, as well as in technical-grade gases including nitrogen, argon, methane, hydrogen, carbon dioxide and pure water vapour. Although the temperature of the plasma is very low, the population of energetic states is sufficient to induce physical/chemical changes on the surfaces of a range of nanostructured materials and semiconductors, such as graphene oxide, titanium dioxide, perovskites, and others, resulting in various changes to crystallinity, optoelectronic, and wettability properties depending on the gas employed for plasma generation. The low temperature of the plasma and rapid treatment times, in the order of 1-10s, enables the integration of plasma processing into roll-to-roll manufacture, a significant step forward in commercial viability within the emerging field of flexible and printed electronics. This study provides an example of rapid $(<1 \mathrm{~min})$ low-temperature plasma processing of indium-tin-oxide electrodes as a replacement for time-consuming chemical treatment before deposition of PEDOT:PSS in a p-i-n perovskite solar cell.
\end{abstract}

Keywords: Plasma treatment, atmospheric plasma, ITO electrode, indium-tin-oxide, perovskite solar cell

\section{INTRODUCTION}

Considerable progress has been made in perovskite photovoltaic technologies have over the past five years. The efficiency for a single-cell came to exceed $25 \%$ in 2019 [1]. One of the key advantages of perovskite solar cells (PSC) is their compatibility with flexible substrates and thus with rapid and low-cost roll-to-roll (R2R) manufacturing [2]. On the other hand, the methods currently employed in the fabrication of PSCs are very slow and barely compatible with R2R. An example may be found in the pre-treatment/cleaning of transparent electron-transporting electrodes, the surfaces of which must be ultra-clean. Indium-tin-oxide (ITO) is a frequent choice for a transparent conductive oxide but its surface naturally contains large quantities of contaminants adsorbed from ambient atmosphere. The ITO is usually cleaned by a time-consuming and somewhat complicated sequence of chemical/ultrasonic baths, and the whole process takes $30-60 \mathrm{~min}$. Such an 
extended cleaning time is, however, incompatible with rapid R2R production, since any steps not directly involved in the deposition of materials must be completed in the shortest possible time.

Electrical plasmas can provide an excellent means of integration into R2R lines; the plasma has the capacity to remain cool and simultaneously contains energetic particles that gently remove the contaminants from the surfaces without negative effects on the bulk structure. In the author's previous work, diffuse coplanar surface barrier discharge plasma has been used to clean and activate ITO surfaces [3]. It was disclosed that plasma treatment of ITO is a relatively simple and efficient method for ITO cleaning; the water contact angle decreased from $84^{\circ}$ to $13^{\circ}$ in just 1 second of plasma treatment. As the plasma was generated in an open-air atmosphere and on a large scale, such an approach finds highly appropriate application in sheet-to-sheet or R2R production of devices that require cleaning of ITO in the minimum possible time. Also recently published have been accounts of the plasma treatment of flexible PET/ITO surfaces in various oxygen-nitrogen atmospheres, including synthetic air $[4,5]$.

\section{EXPERIMENTAL}

\subsection{Materials}

Perovskite solar cells with p-i-n architecture (Figure 1a) were fabricated using $\mathrm{CH}_{3} \mathrm{NH}_{3} \mathrm{Pbl}_{3-\mathrm{x}} \mathrm{Cl}$ x perovskite films. These films were created from a formulation of methylammonium iodide (MAl), $\mathrm{PbCl} 2$ and $\mathrm{Pbl} 2$ at a molar ratio of 1:1:4 (PbCl2:Pbl2:MAI) in a DMF solvent obtained from Ossila (I201, Ossila Ltd., UK). The deposition of the perovskite layers was performed in a nitrogen glove box. The materials used for the fabrication of the p-i-n solar cells were: glass/ITO electrode (S101, Ossila), spin-coated poly(3,4ethylenedioxythiophene) polystyrene sulfonate (PEDOT:PSS) (Heraeus Clevios P VP Al 4083), spin-coated Perovskite (I201, Ossila Ltd., UK), spin-coated PCBM (M114, Ossila Ltd., UK), and an evaporated Au counterelectrode.

\subsection{Chemical treatment of ITO}

The ITO substrates were chemically pre-cleaned by a four-step procedure: 1) 20 min ultra-sonication in deionized water with detergent; 2) Drying in air; 3) 20 min ultra-sonication in isopropyl alcohol; 4) Drying in air, $30 \mathrm{~min}$ in UV chamber (ELG100S, 40 W, 253 nm, Dinies Technologies GmbH, Germany).

\subsection{Plasma treatment of ITO}

Low-temperature atmospheric-pressure ambient-air plasma was generated by an RPS40+ (Robust Plasma Systems - Roplass s.r.o., Czech Republic) equipped with dielectric barrier discharge integrating a coplanar arrangement of the electrode system - a device also known as a diffuse coplanar surface barrier discharge (DCSBD) plasma unit (Figure 1b). The width and inter-electrode distance between the coplanar electrodes were $0.5 \mathrm{~mm}$ and $0.5 \mathrm{~mm}$, respectively. The area of the RPS40+ plasma was $50 \times 25 \mathrm{~mm}$ and power input into plasma was $40 \mathrm{~W}$. Areal power density was $3.2 \mathrm{Wcm}^{-2}$ and volume power density was $160 \mathrm{Wcm}^{-3}$. The temperature of the alumina ceramics did not exceed $60^{\circ} \mathrm{C}$. The plasma treatment was performed in a nitrogen atmosphere, directly simple procedure in a nitrogen glove-box.

\subsection{Solar cell characterization}

Power conversion efficiency (PCE) measurements were taken under standard conditions by solar simulator with a $1.5 \mathrm{G}$ air-mass (AM) filter. The simulated light intensity was adjusted to $1000 \mathrm{~W} / \mathrm{m}^{2}$ with an NRELcalibrated Si solar cell. A shadow mask with an active area of $0.045 \mathrm{~cm}^{2}$ was used during the measurements. All the prepared perovskite solar cells were measured in reverse scan sequence, starting at $1.2 \mathrm{~V}$. 


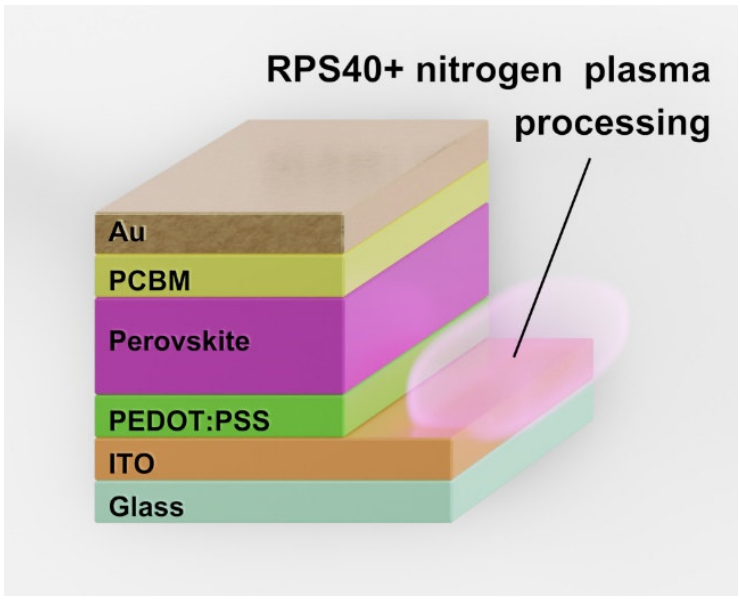

a)

Figure 1 a) Structure of $p$-i-n perovskite solar cell with indication of plasma processed ITO layer and b) Robust Plasma System 40+ (RPS40+) manufactured by Roplass s.r.o. (Brno, Czech Republic)

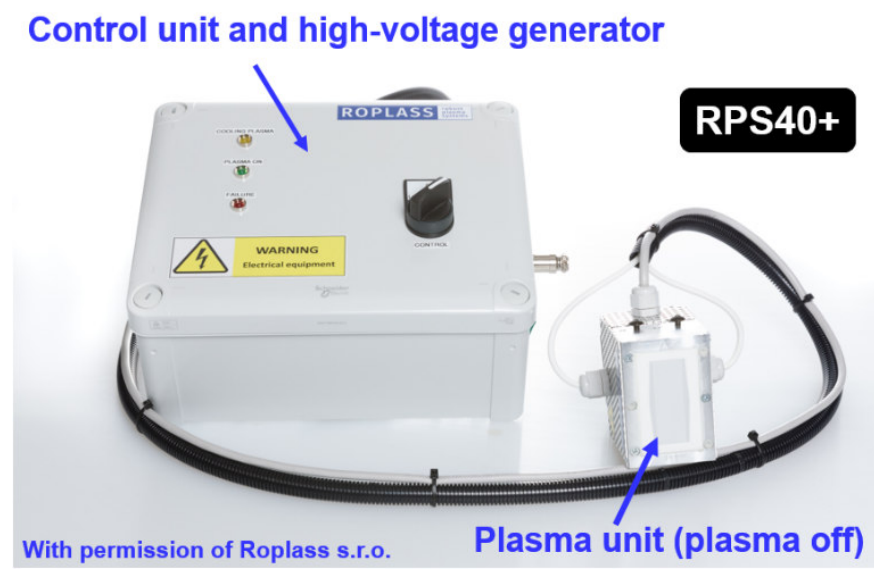

b)

\section{RESULTS AND DISCUSSION}

Both chemical treatment and plasma treatment were employed to clean the ITO electrode prior to deposition of PEDOT:PSS. The wettability of PEDOT:PSS on the ITO surface was measured in terms of the contact angles of PEDOT:PSS droplets deposited on the ITO surfaces. The untreated ITO surfaces exhibited a PEDOT:PSS contact angle of $92.3^{\circ} \pm 1.9^{\circ}$. After chemical treatment, the contact angle decreased to $75.3^{\circ} \pm 2.9^{\circ}$. Plasma treatment proved far more time-efficient. After very brief exposure to plasma, the contact angle decreased to approx. $75.2^{\circ} \pm 3.5^{\circ}$, a result that, while similar to that of chemical treatment, was achieved in a mere $0.25 \mathrm{~s}$, as against the $60 \mathrm{~min}$ (approx.) required for the chemical approach. Plasma treatment times longer than $1 \mathrm{~s}$ yielded

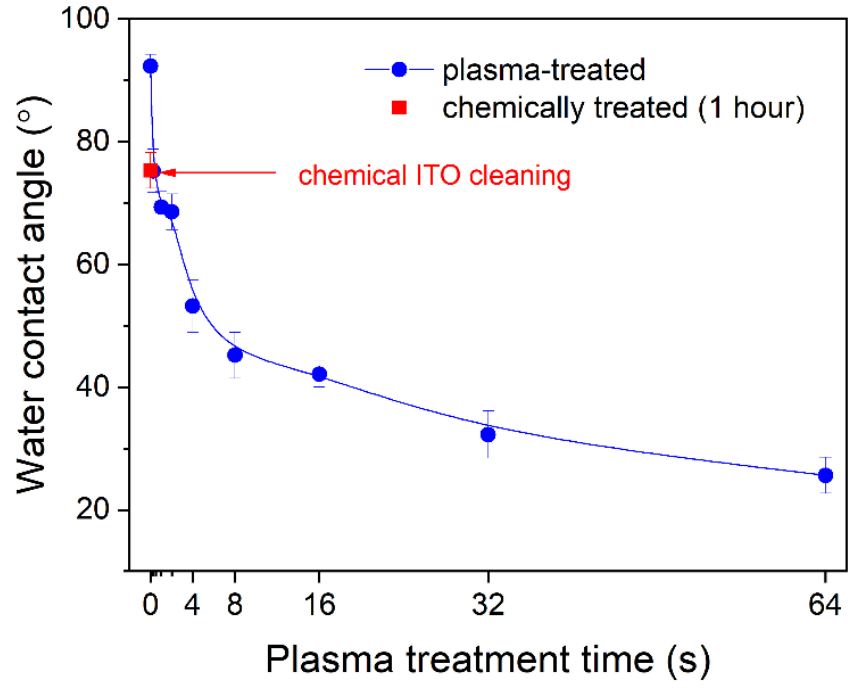

Figure 2 PEDOT:PSS contact angles on ITO surfaces treated in plasma for $0.25 \mathrm{~s}-64 \mathrm{~s}$ contact angles of lower values, and after plasma treatment for $16 \mathrm{~s}$ the contact angle of PEDOT:PSS decreased to $42.1^{\circ} \pm 2.1^{\circ}$. Plasma treatment for $64 \mathrm{~s}$, the maximum time tested, led to a contact angle of $25.6^{\circ} \pm 3.0^{\circ}$. This constitutes clear evidence that atmospheric pressure plasma treatment leads to a far superior effect on the wettability of ITO electrodes prior to deposition of PEDOT:PSS.

The chemically-treated and plasma-treated ITO surfaces were tested in p-i-n perovskite solar cells. The j-V curves of a number of samples with the ITO electrode treated chemically or in plasma, for various times, appear in Figure 3a. A summary of the short-circuit current (jsc), open-circuit voltage (Voc), fill factor (FF) and power conversion efficiency (PCE) for all the samples tested appears in Table 1. ITO which had not been cleaned, with a contact angle of $95^{\circ}$, was not functional in the PSC since PEDOT:PSS could not wet its surface. The results for the PSC with chemically-treated ITO were jsc $16.22 \mathrm{~mA} / \mathrm{cm}^{2}, V_{\text {oc }} 867.23 \mathrm{mV}$, and FF 62.72. Power 
conversion efficiency was $8.64 \%$. The figures for the perovskite ink used in this study (I201, Ossila) were, according to the manufacturer, a maximum PCE of $11.83 \%$, with jsc $16.51 \mathrm{~mA} / \mathrm{cm}^{2}, V_{\mathrm{oc}} 0.91 \mathrm{~V}$, and FF $78 \%$.

The PSC with an ITO treated in plasma for $0.5 \mathrm{~s}$ exhibited considerable improvement in wettability (Figure 2), similar to that of chemically-treated ITO. However, the jsc, VOC, FF, and PCE were much lower than in the PSC with a chemically-treated ITO. The development of the PCE with the plasma treatment over time appears in Figure 3b. Prolonging the plasma treatment time to $2 \mathrm{~s}$ led to significant improvement in the jsc, $\mathrm{V}_{\mathrm{oc}}, \mathrm{FF}$, and PCE, which then achieved $16.14 \mathrm{~mA} / \mathrm{cm}^{2}, 842.11 \mathrm{mV}, 64.61$, and $8.78 \%$, respectively. The PSC with a 2s plasma-treated ITO electrode gave very similar figures to those of the PSC with chemically-treated ITO. Figure 2 shows that prolonging the plasma treatment time led to improvement in the wettability of the PEDOT:PSS on the ITO surface. However, extending the plasma treatment time to $16 \mathrm{~s}$ had no further impact on PSC properties; the jsc, Voc, FF, and PCE remained at the same level as that of the PSC with ITO treated in plasma for $2 \mathrm{~s}$. Thus, a water contact angle of $60^{\circ}-70^{\circ}$ proved adequate for good wettability of the PEDOT:PSS. Further improvements in the wettability are not required and had no effect on the properties of the PSC.

Table 1 Photovoltaic conversion parameters of fabricated $p-i-n$ perovskite solar cells

\begin{tabular}{|l|c|c|c|c|c|}
\hline p-i-n PSC with ITO electrode cleaned in plasma for various times & $\begin{array}{c}\mathbf{j}_{\mathbf{s c}} \\
\left(\mathbf{m A} / \mathbf{c m}^{2}\right)\end{array}$ & $\begin{array}{c}\mathbf{V}_{\mathbf{~}} \\
(\mathbf{m V})\end{array}$ & $\begin{array}{c}\mathbf{F F} \\
\mathbf{( \% )}\end{array}$ & $\begin{array}{c}\mathbf{n} \\
\mathbf{( \% )}\end{array}$ \\
\hline Not cleaned & \multicolumn{2}{|c|}{ Poor wettability of PEDOT:PSS on ITO } \\
\hline Chemically cleaned & 16.22 & 867.23 & 62.72 & $\mathbf{8 . 6 4}$ \\
\hline 0.5-s plasma & 11.32 & 746.88 & 53.84 & $\mathbf{4 . 4 5}$ \\
\hline 1-s plasma & 14.34 & 790.13 & 61.80 & $\mathbf{7 . 0 5}$ \\
\hline 2-s plasma & 16.14 & 842.11 & 64.61 & $\mathbf{8 . 7 8}$ \\
\hline 4-s plasma & 16.12 & 889.29 & 63.21 & $\mathbf{9 . 0 6}$ \\
\hline 8-s plasma & 15.63 & 861.56 & 62.45 & $\mathbf{8 . 3 9}$ \\
\hline 16-s plasma & 15.57 & 857.65 & 62.99 & $\mathbf{8 . 4 2}$ \\
\hline
\end{tabular}

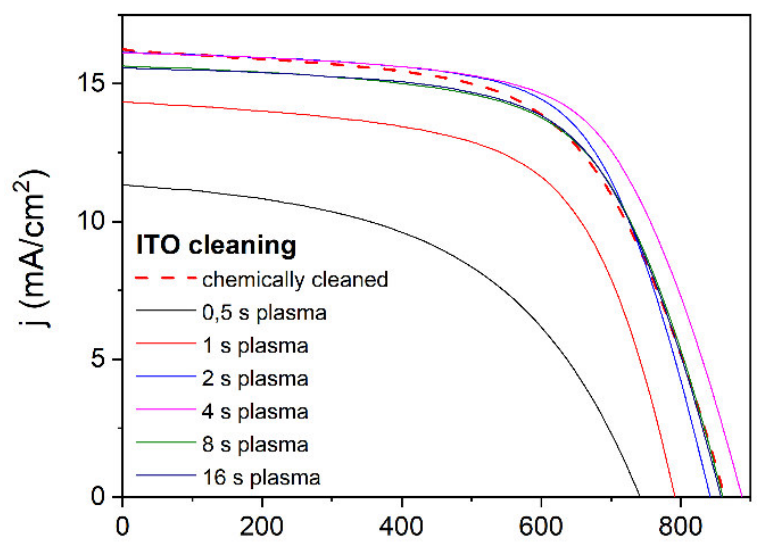

a)

$\mathrm{V}(\mathrm{mV})$

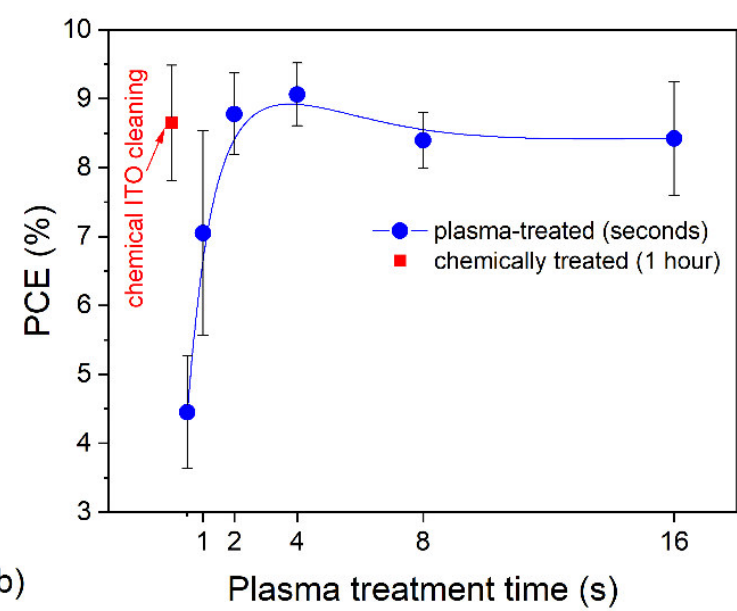

Figure 3 a) j-V curves and b) PCEs for PSCs with ITO electrode chemically treated and plasma treated for various times 


\section{CONCLUSION}

This study demonstrates that time-consuming chemical treatment of ITO electrode in PSC easily be replaced by time-efficient, low-temperature nitrogen plasma treatment. The RPS40+ plasma system can be operated simply in a nitrogen glove-box, which makes manipulation of the samples easy and efficient. The currentlywidespread processing of ITO electrodes by chemical procedures involves a sequence of chemical/ultrasonic baths, rendering the preparation of ITO surfaces in PSCs long and impractical. In sharp contrast, plasma treatment of the ITO surface takes only two seconds and the overall parameters of a PSC with plasma-treated ITO, including FF and PCE, stand at around the same values as those for a PSC with a chemically-treated ITO. The clear benefit of plasma lies not only in saving valuable time; it is revealed as a new methodology for integration into fast roll-to-roll manufacturing of flexible devices with ITO electrode systems.

\section{ACKNOWLEDGEMENTS}

This research was supported by the GAČR projects 19-14770Y and 19-23718S.

\section{REFERENCES}

[1] Best Research-Cell Efficiency Chart. https://www.nrel.gov/pv/cell-efficiency.html. Accessed 8 Aug 2019.

[2] CHANG, N. L., HO-BAILLIE, A. W. Y., VAK, D., GAO, M., GREEN, M. A., EGAN, R. J. Manufacturing cost and market potential analysis of demonstrated roll-to-roll perovskite photovoltaic cell processes. Sol. Energy Mater. Sol. Cells. 2018. vol. 174, pp. 314-324.

[3] HOMOLA, T., MATOUŠEK, J., MEDVECKÁ, V., ZAHORANOVÁ, A., KORMUNDA, M., KOVÁČIK, D., ČERNÁK, M. Atmospheric pressure diffuse plasma in ambient air for ITO surface cleaning. Appl. Surf. Sci. 2012. vol. 258, no. 18, pp. 7135-7139.

[4] HOMOLA, T., SHEKARGOFTAR, M., DZIK, P., KRUMPOLEC, R., ĎURAŠOVÁ, Z., VESELÝ, M., ČERNÁK, M. Low-temperature $\left(70^{\circ} \mathrm{C}\right)$ ambient air plasma-fabrication of inkjet-printed mesoporous $\mathrm{TiO} 2$ flexible photoanodes. Flex. Print. Electron. 2017. vol. 2, no. 3.

[5] SHEKARGOFTAR, M., KRUMPOLEC, R., HOMOLA, T. Enhancement of electrical properties of flexible ITO/PET by atmospheric pressure roll-to-roll plasma. Mater. Sci. Semicond. Process. 2018. vol. 75, pp. 95-102. 